\title{
Massive bleeding in polytrauma: how can we make progress?
}

\author{
Jean-Louis Vincent ${ }^{*}$, Richard Dutton ${ }^{2}$, Michael Parr ${ }^{3}$ and Carl Hauser ${ }^{4}$
}

\begin{abstract}
Trauma is a major cause of death worldwide, with some $30 \%$ of deaths associated with hemorrhage. Rapid control of bleeding in such patients is thus an essential aspect of trauma care. Recombinant human factor VIla is sometimes used off-label in massively bleeding patients and has been demonstrated in two randomized trials to significantly reduce the need for blood transfusions. Whether this translates into improved outcomes has not been determined, most notably because mortality appears to be much lower than in the past as a result of improved general care of trauma patients. In this setting it may be increasingly difficult to demonstrate that any intervention can influence survival since the number of patients needed for sufficient power is so high and the duration needed for recruitment of the patients too long. In the present commentary, we reflect on how we can move forward in the management of severely bleeding trauma patients in the current environment.
\end{abstract}

Recombinant human factor VIIa (rFVIIa) is often used off-label in massively bleeding patients. A recent review of use in the USA [1] and a meta-analysis of studies for nonapproved indications [2] document the frequent use of rFVIIa in a variety of clinical conditions characterized by a real risk of death or major morbidity from exsanguination.

The literature demonstrates an association between use of rFVIIa and increased risk of arterial thromboembolic complications [3]. This increased risk is, of course, a predictable side effect of a procoagulant drug, and can actually be regarded as proof of its physiologic effect. These recent studies have raised doubts about the

*Correspondence: jlvincen@ulb.ac.be

'Department of Intensive Care, Erasme Hospital, Université Libre de Bruxelles,

Route de Lennik 808, 1070 Brussels, Belgium

Full list of author information is available at the end of the article advisability of giving this product to massively bleeding patients, and have prompted some hospitals to ban or restrict the use of the drug in hemorrhaging patients. Yet the efficacy of rFVIIa as a hemostatic agent is actually well established. Perhaps the numerous case reports on the cessation of bleeding will not be entirely convincing to all defenders of evidence-based medicine, but the results from prospective randomized, placebo-controlled trials should be.

Two double-blinded randomized, placebo-controlled trials have convincingly demonstrated that administration of rFVIIa in massive bleeding can reduce the need for blood transfusions $[4,5]$. In the first trial, red blood cell transfusion was significantly reduced in patients with blunt trauma. Moreover, just 14\% of rFVIIa-treated blunt trauma patients received massive transfusions compared with $33 \%$ of placebo-treated patients $(P=0.03)$; in penetrating trauma, $19 \%$ of the placebo-treated patients received massive transfusions compared with only $7 \%$ of the treated group $(P=0.08)$. In the second trial, which was conducted to examine the 30-day mortality of patients receiving rFVIIa, the number of units of red blood cells administered to blunt trauma patients (the majority of patients studied) was significantly less in rFVIIa-treated patients than in placebo-treated patients (6.9 vs. 8.9 units, $P=0.04$ ). The same was true for the number of units of fresh frozen plasma administered (4.7 vs. $6.9, P<0.01)$.

Despite decreasing blood use, this latter study was not able to demonstrate a significant reduction in mortality the primary endpoint - with rFVIIa use because the overall mortality in this entire cohort of severely injured patients was only $11 \%$, and the trial had been powered based on the observed historical mortality of 25 to $30 \%$ in similarly injured patients [5]. This pivotal trial was therefore stopped early, for scientific futility. The authors attributed the overall decrease in mortality of the entire cohort to advancing global standards in trauma care and to the meticulous application of evidence-based principles for resuscitation, transfusion and critical care management to all patients.

In these circumstances, especially bearing in mind the heterogeneity of trauma patients, it is virtually impossible 
to demonstrate a reduction in mortality. The number of patients that would be required becomes prohibitive, as does the amount of time that would be needed to perform such a study: 573 patients were recruited over 3 years in the CONTROL study [5]. During prolonged study periods like this, important practices may change, influencing outcomes. Similarly, global improvements in the management of acute respiratory failure and decreases in permanent renal failure have made the observation of changes in major morbidities in these populations difficult.

These observations raise two important issues. First, will it be possible to conduct trials in massively bleeding patients or in polytrauma victims? If we cannot demonstrate a reduction in mortality or morbidity rates, what should be the endpoints of further studies? What kinds of studies should we propose in order to define the place of rFVIIa or the newer procoagulants that are now emerging? Second, what can we reasonably do the next time we are about to lose a young trauma victim to exsanguination? Should we give rFVIIa and risk being accused of off-label use of a drug without an accepted benefit-risk profile, or should we deny the patient the benefit of a potentially life-saving product that clearly reduces bleeding?

What the clinician needs is an understanding of risks and benefits that can be artfully applied to the care of individual patients. Clearly, almost any therapy is justified at some level of risk of patient death, no matter how unlikely it is to succeed. But how should this risk be assessed? How should imminent death be weighed against the risk of future complications, especially if they can be prevented or treated in a surviving patient?

Experienced high-volume trauma centers, including British and American military hospitals in Iraq and Afghanistan, have seen their use of rFVIIa fall in recent years (see Figure 1 in [1]). This fall in use is thought to be the result of an improved understanding of damage control resuscitation, and of a natural centering of the pendulum of enthusiasm for rFVIIa. But use has not fallen to zero. There remain situations - at least in the practice of the most experienced trauma clinicians when use of rFVIIa is both appropriate and life-saving. As with other interventions in intensive care, it is likely that the greatest effect of rFVIIa will come if it is used early, and late administration is more likely to be futile. Better methods of identifying early those patients who are most likely to benefit are needed to help guide the appropriate use of rFVIIa. Importantly, too, in contrast to prospective, randomized trials in older populations [3], studies of rFVIIa in trauma have not demonstrated an increased risk of thromboembolic complications above the baseline $[4,6]$. The risk of arterial thrombosis is probably related to the presence of occult endothelial disruption from specific injuries, making individual clinical assessment even more important.

Reactive restrictions to off-label use of rFVIIa may represent the loss of both the baby and the bathwater. We prefer to advocate respect for the judgment of clinicians who must make hard choices in the management of highrisk patients, and call for continued research to support their true need - a better understanding of which patients will benefit from procoagulant therapies, and of the real incidence and severity of risks.

Abbreviations

rFVIla, recombinant human factor VIla.

\section{Competing interests}

$\mathrm{J}-\mathrm{LV}, \mathrm{RD}$ and MP have received consulting fees and grant support from Novo Nordisk. CH declares that he has no competing interests.

\section{Author details}

'Department of Intensive Care, Erasme Hospital, Université Libre de Bruxelles, Route de Lennik 808, 1070 Brussels, Belgium. ${ }^{2}$ Anesthesia Quality Institute, 520 N. Northwest Highway, Park Ridge, IL 60068-2573, USA. ${ }^{3}$ Intensive Care Unit, Liverpool Hospital, University of New South Wales, Elizabeth Street, Liverpool, NSW 2170, Australia. ${ }^{4}$ Department of Surgery, Beth Israel Deaconess Medical Center, Harvard Medical School, 330 Brookline Avenue, Boston, MA 02215, USA.

Published: 11 October 2011

\section{References}

1. Logan AC, Yank V, Stafford RS: Off-label use of recombinant factor VIla in U.S. hospitals: analysis of hospital records. Ann Intern Med 2011, 154:516-522.

2. Yank V, Tuohy CV, Logan AC, Bravata DM, Staudenmayer K, Eisenhut R, Sundaram V, McMahon D, Olkin I, McDonald KM, Owens DK, Stafford RS: Systematic review: benefits and harms of in-hospital use of recombinant factor VIla for off-label indications. Ann Intern Med 2011, 154:529-540.

3. Levi M, Levy JH, Andersen HF, Truloff D: Safety of recombinant activated factor VII in randomized clinical trials. N Engl J Med 2010, 363:1791-1800.

4. Boffard KD, Riou B, Warren B, Choong Pl, Rizoli S, Rossaint R, Axelsen M, Kluger Y; NovoSeven Trauma Study Group: Recombinant factor VII as adjunctive therapy for bleeding control in severely injured trauma patients: two parallel, randomized, placebo-controlled, double-blind clinical trials. J Trauma 2005, 59:8-15.

5. Hauser CJ, Boffard K, Dutton R, Bernard GR, Croce MA, Holcomb JB, Leppaniemi A, Parr M, Vincent JL, Tortella BJ, Dimsits J, Bouillon B; CONTROL Study Group: Results of the CONTROL Trial: efficacy and safety of recombinant activated factor VII in the management of refractory traumatic hemorrhage. J Trauma 2010, 69:489-500.

6. Dutton RP, Parr M, Tortella BJ, Champion HR, Bernard GR, Boffard K, Bouillon B, Croce MA, Dimsits J, Holcomb JB, Leppaniemi A, Vincent UL, Hauser CJ; CONTROL Study Group: Recombinant activated factor VII safety in trauma patients: results from the CONTROL Trial. J Trauma 2011, 71:12-19.

doi:10.1186/c10438

Cite this article as: Vincent J-L, et al:: Massive bleeding in polytrauma: how can we make progress? Critical Care 2011, 15:196. 